\title{
Mental Representations and Perception of People with Other Ethnicity (On the Example of Psychosemantic Experiment in Four Russian Regions)
}

\author{
Svetlana Maximova ${ }^{1}$, Daria Omelchenko ${ }^{1}$, Maxim Maximov ${ }^{1}$, Oksana Noyanzina ${ }^{1}$, Natalia \\ Goncharova $^{1}$, Svyatoslav Semaynov ${ }^{1}$ \\ ${ }^{1}$ Altai State University, 61, Lenina str., 656049, Barnaul, Russian Federation
}

\begin{abstract}
The paper presents the analysis of mental representations, evaluations and stereotypes construing the general image of the 'Other' in public consciousness, shaped through personal experience of interaction with representatives of different nationalities and stereotypes, both positive and negative, translated by mass-media, mass culture and political elites. It gives a comprehensive description of semantic interrelations between attributes relevant to different social roles that may be performed by a representative of the other ethnicity; discovers latent factors conditioning the perception of different ethnic images and analyzes semantic spaces visualizing categorical structures of the consciousness mentality of social groups of different gender, age and region of residence. Authors conclude that the core representations are related to evaluation of the potential risk and the threat to national security, ethnic conflicts and tension, social inequality and low cultural or intellectual level. The influence of these strongly stereotyped representations is manifested in less extent in close interpersonal relations and in greater extent in conditions of relations with unknown people with low social status of illegal immigrants. Self-perception of Russian citizens is rather contradictory, assembling paternalistic view on other nationality, national uniqueness and superiority with a low self-esteem. Regional mentalities are significantly differentiated and reflect socio-economic and ethno-cultural peculiarities if their residents.
\end{abstract}

Keywords: Mental representations, social representations, psychosemantics, repertory grid, image of the 'other', ethnicity, migrants, refugees, migrant workers.

\section{Introduction}

The contemporary world is torn by multiple contrarieties, related to the objective multi-polar character of the world order, the spread of universally accepted culture codes and local cultures' struggle for survival and preservation, the attempt of transnational organizations to find unified ways and mechanisms of counteraction against global challenges and threats. In today's Russia, these processes influence the social and cultural life as well, and are strongly associated with internal economic and foreign policy problems. Highly dynamic and emotional events on the global and national stages, determined by the permutation of forces at the political map of the world, resulted in the significant transformation of extra-images of peoples and countries as well as of internal national images, formed on the base of the feeling of 'we-ness'. The image of the 'Other', generated by means of socio-psychological mechanisms of comparison, categorisation, differentiation and identification, and represented in verbal and visual forms, offers a frame for social actions, a program, following which the individuals shape their behaviour and expectations from people whose ethnicity differ from their own. Exploring different images of ethnic 'Other', revealing the peculiarities of their construction in the public conscience we try to explicate existing attitudes, stereotypes and representations, determining the specific of interethnic relations in Russia.

\section{Theoretical and methodological basis of research}

\subsection{Initial theoretical observations}

Nowadays the notion of «mental representation» is broadly used in cognitive and psychological sciences. Despite of the great number of theoretical and empirical studies there is no agreement about the definition and the content of this scientific category. It is partially caused by initial polysemy of both words within the expression. Thus, the term «mental» may be interpreted as «psychic», «intellectual», «ideate», «related to 
memorization», and «representation» could be defined as «presentation» or «image». The use of the notion of mental representation in scientific discourse is conditioned by the necessity of understanding and analysis of objective laws of reflection of the social realm by the subject, realize different models of behavior, responding to actual situation and given tasks.

Psychological researches focused on mental representations are usually concentrated on explanation of how information perceived by receptors is decoded at the level of analyzing structures of brain and becomes knowledge about reality which is necessary for effective adaptation. Even «elementary» sensations are represented in the conscience in a treated mode. So, interaction with an environment is mediated by mental representations, resulting from structural and analytical activity of complexly organized cognitive system. While representation is not an exact analogue of perceived reality, its main quality is subjectiveness.

Evolution of scientific knowledge about mental representations was strictly associated with growing interest towards mechanisms of getting, analyzing and storage of information as well as towards human intellectual abilities. Cognitive sciences had made several steps from the conviction that the psyche is a «tabula rasa» perceiving all information from external world to acknowledgement of importance of internal conditions and experience in representation's formation.

Nevertheless, in the modern cognitive psychology there is no unique understanding about what is indeed mental representation. Some authors define mental representations as a content of psychic reflection, a result of perception. Other theories treat mental representations as mechanisms of formation of images, systems of categories and mental maps, assuring purposeful and adequate to external conditions subject's behavior. Primarily, the study of mental representations was strictly related to semiotic problematic, for it was supposed that the unit of ideation possessed verbal meaning. Later, some important theories were elaborated to accept the existing of different kinds of coding, including without notion of natural language. Thus, A. Paivio put forward a hypothesis that there are two ways a person could expand on learned material: verbal associations and visual imagery [1].

In works written by S.M. Kosslyn two types of representations are described - analogue and propositional (abstract). Analog representations (quasi-pictorial or depictive representations) suppose that there is a correspondence between the parts of the representation and the parts of the thing being represented and these analog representations are extremely useful things that are important in memory and thought. Abstract representations are constructed according to certain syntax, modally unspecific and discrete [2].

In Russian psychology the problematic of mental representations is investigated in the frame of multiple studies of perceptive images formation (as a result of psychic activity). An important meaning for the expansion of scientific representations about the structure of the conscience had the conception of the world-view, suggested by A.N. Leontiev. The scientist has elaborated a category of personal sense, reflecting the phenomenon of selectiveness and subjectivity $\mathrm{s}$ of the perception of surrounding world [3]. Besides, A.N. Leontiev has put a hypothesis about the existence of the fifth dimension of a subject - the dimension of meanings. Without great simplification we may say that the world-view is the system of mental representations.

In seminal works by E.Yu. Artemieva, a hypothesis was tested that "some traces of activities form sustainable systems, structuring external influences". Analyzing structures of subjective experience, the researcher had classified the world levels as modal (superficial) and nuclear (amodal, semantic) systems. Criteria of extraction of these levels of psychic reflection were based on stages of formation of psychic trace, left after interaction with objects od surrounding world (level of sensory perception and level of representations), and peculiarities of the language of its description (modal, semantic and amodal coding). According to given differentiation of subjective experience levels, the author describes its units: "presense" (level of perceived world), "senses" (level of subjective semantics) and "personal senses" (constituting the world-view) [4].

With regard to our research, the usage of classical theories of perception, elaborated in the frame of general psychology in the context of principal cognitive processes exploration, would be difficult, for it concerns unifying characteristics of social objects - social communities and groups. That is why we propose integrative methodology based on social constructivist approach.

Different axes of theoretical analysis and sociological reflexion about social kinds of mental representations may be defined. The social analysis of political realities and images of states was given by B. Anderson [5], and H. Arendt [6], the useful standings about the social determination of existing representations might be found in 
postclassical discourse (Z. Baumann; U. Beck; J. Baudrillard; P. Bourdieu) [7-10], theories of mentality (P. Moscovici; P. Sorokin) [11, 12] and social class structure (M. Halbwachs) [13].

The common moment of all described theories is the statement about the influence of internal structures and models, represented in verbal and nonverbal forms, and determined by definite peculiarities of the social system, on thinking and behaviour of individuals. These statements underline the necessity and the importance for the social life reproduction of that typical, categorically organized perception of social reality by the subject and the impossibility of interaction beyond the accepted system of symbols and meanings.

\subsection{Methods and data analysis tools}

The exploration of mental representations, reflecting existing attitudes towards persons with the same or other ethnicity forced us to choose the methodological instrument which could describe the contents of mental representations in public conscience. Psychosemantic approach appeared as the most relevant for aims of our research for it considers the personality as the wearer of complex world view, including representations about external and internal objects and phenomena $[14,15]$. The main task of psychosemantics is to reconstruct the system of meanings which individuals attribute to the world, other people and to themselves, as well as to explore its genesis, structure and functioning.

Psychosemantic experiment was conducted in four regions of Russian Federation (Altaisky krai, Omskaya oblast, Krasnoyarsky krai, Republic of Altai) by means of questionnaire, designed as a combined version of multiple identifications method, semantic differential and repertory grid technic ( $n=240$, aged 15-17 years).

Objects of evaluation represented social roles which bearers of 'own' and 'alien' ethnic identity may perform in everyday social contacts, differentiated by level of social distance, legality, forced/ unconstrained character of sojourn: 'nearest person of other nationality', 'representative of other ethnos, who was born and constantly lives in region', 'refugee', 'migrant worker (legal or illegal)', 'representative of other ethnos, who came with educational or cultural purpose (tourist)' and reference position 'native (aboriginal) citizen of Russia'.

All objects were assessed with twenty one 7-point bipolar scales, elaborated on the base of the classical three-component structure of attitude, including emotional and evaluating (items 1, 2, 4-7, 11-17, 19), cognitive $(3,10,20,21)$ and conative $(8,9,18)$ components: 1) peaceful - aggressive; 2$)$ strong - weak; 3$)$ poor - rich; 4) subtle, enterprising - naïve, artless; 5) well-wishing - hostile; 6) intellectually and culturally developed intellectually and culturally poor; 7) close - alien; 8) breaks the law, violates public order - observes the law, maintains public order; 9) respects Russian national traditions and culture - destructs Russian national traditions and culture; 10) discriminated - exercises fully rights and freedoms; 11) egoistic, devoted to one's own interests and advancement - altruistic, capable of self-sacrifice; 12) irritant, inspiring disgust - non-irritant; 13) trustworthy - mistrustful; 14) (not)evoking fear; 15) (not) evoking compassion; 16) evoking superiority (humility); 17) associated with national exceptionality - associated with national diversity; 18) stands apart, has different way of life -stands together, adopts way of life, behavior and habits; 19) inspires respect - inspires enmity; 20) represents a threat for national security, social-economic development of Russia - does not represent a threat; 21) is (not) a source of interethnic conflicts and tension.

Primary data were analyzed by means of descriptive statistics, t-tests, one-way ANOVA and multivariate MANOVA. Then, CatPCA analysis was fulfilled with group matrices of data, aggregated by sex, age and region of residence, to obtain models of categorical structures of conscience - 'semantic spaces', revealing particularities of mental representations of generalized "strangers" [9]. Coordinates axes for semantic spaces were chosen by means of factor analysis, while the content of extracted factors - bases for categorization characterized the forms of generalizations and personal constructs - ensemble of interrelated and intercorrelated features, forming personal cognitive structures for interpretation and prediction of the reality.

\section{Results and Discussion}

The general descriptive analysis of object profiles has shown that main differences between them were related to social identification, social security and social inequality. The position 'nearest person of other nationality' (friend, member of the family) was associated to security and peacefulness, as well as to emotional perception of this image, inspiring trust and respect. The role 'representative of other ethnos, who was born and constantly lives in region' was evaluated as a bit less peaceful, inspiring trust, but at the same time evoking less 
pity and compassion. The key characteristics profile of the 'refugee' were pity and compassion, and this role was perceived as discriminated against, poor and alien. The 'migrant worker' had the most negative emotional assessment than previous positions and was evaluated as alien, less worthy of respect and trust. This role was associated with interethnic conflicts and social tension, isolation and alienation. The position of 'tourist' was the most attractive and idealized, in the conscience of respondents its main characteristics were "peaceable", "intellectually and culturally developed", "well-wishing", "rich", "enjoying rights and freedoms", "not representing a threat for national security". It didn't evoke irritation even if he was perceived as alien, not evoking pity and compassion, subtle and enterprising. The 'native (aboriginal) citizen of Russia' was evaluated as definitely 'own', peaceable, not representing a source for interethnic conflicts nor a threat for national security, nor evoking fear, but at the same time as poor and cunning, evoking pity and compassion, and evoking the sense of national exceptionality. Thus, close friends, members of the family and inhabitants of the region were perceived as trusty, respectable and intimate. 'Tourist', 'migrant worker' and 'refugee' were marked as 'aliens', but if 'tourist' was evaluated as law-abiding, rich, well-wishing, intellectually and culturally developed, two other positions received were treated as poor, discriminated, representing a threat for social security and Russian culture and traditions. Besides, 'migrant worker' was associated with public order violence and interethnic tension. The image of 'native (aboriginal) citizen of Russia' had contradictory characteristics and was described by amalgam of spirit of enterprise and poverty, power and pity, peacefulness and law violation, associated with national exceptionality and superiority. This position received the highest rates of 'ownness', leaving behind friends and relatives of other nationality, that led us to confirm that mechanisms of national and cultural identification function even in conditions of close interethnic relations, preserving priority over them.

Multivariate tests showed statistically significant association between independent factors (sex, age, region of respondent) and the complex of dependent variables. The factor of sex was significant only for several variables and emerged in evaluation of interpersonal relations, richness-poverty of aboriginals and regional ethnic groups (females' rates were always higher, t-test, $\mathrm{p}<0.05$ ). The impact of age was significant for all positions except migrant worker and native citizens, assessments corresponding to respondents from middle age and older groups were rather high and similar, opposed to lowest values of young people. The factor of region was the most important for roles of refugee and migrant worker. Regional specific consisted in different evaluation of social-economic characteristics and emotional reactions, determined by economic status of region and their ethno-cultural peculiarities. Respondents from regions with higher standards of living (Omskaya oblast, Krasnoyarsky krai) also had higher assessments of well-being of other ethnos, born and constantly living in the region, whereas inhabitants of subsidized regions (Altaisky krai and Republic of Altai) treated them as poor and deprived of rights. The similar tendency was relevant for the position of 'Tourist'. In wealthier regions it was described rather moderately, whereas in poorer regions 'tourist' was perceived as more well-off and prosperous, possessing fully human rights and freedoms.

In order to find semantic mechanisms, mediating the perception of ethnic 'Other' principal factor analysis for categorical variables (CatPCA) was used for its possibilities to deal with heterogeneous scales and to build biplots including coordinates for objects of evaluation and descriptors. Two-factor solutions were interpreted for each group (general sample, single groups for age, sex and regional samples), the first factor explained 70-80\% of variance, the second $-20-30 \%$, and general explained variance attained $100 \%$.

The factor structure for combined pull of data was the most typical for the population from all four regions. The first factor was defined as 'the holistic acceptance or rejection of the 'other' and fitted well the classical Osgood's evaluative dimension. All variables with significant loadings were related to several axes of meanings: security - danger (items 2, 5, 14, 20,21), social inequality - social justice (items 3,10,15, 16), ethno-cultural relations (items $6,9,18)$ and mentality $(1,11,12,13,19)$. The second factor had on its positive pole characteristics 'associated with ethnic diversity', 'observes the law, maintains public order', 'rich', 'peaceable', 'evoking humility. The negative pole was represented by descriptors 'naïve, artless', 'alien', 'mistrustful' and 'evoking enmity'. Thus, if the first factor was related to interethnic relations in different spheres - political, cultural, peculiarities of mentality and social interactions, the second factor represented opposition founded on axes of power and law, 'owness' and 'strangeness' (Table I). 
5th International Conference on Studies in Humanities and Social Sciences (SHSS-2016) Dec. 5-6, 2016 Singapore

TABLE I: CatPCA results. Factor loadings for two dimensions extracted on the data of united sample

\begin{tabular}{|c|c|c|}
\hline Descriptors & Dimension 1 & Dimension 2 \\
\hline peaceful - aggressive & 0.886 & 0.463 \\
\hline strong - weak & 0.959 & -0.045 \\
\hline rich - poor & 0.901 & 0.395 \\
\hline subtle, enterprising - naïve, artless & 0.359 & -0.928 \\
\hline well-wishing - hostile & 0.995 & 0.043 \\
\hline intellectually and culturally developed - intellectually and culturally poor & 0.998 & -0.023 \\
\hline close - alien & 0.447 & -0.895 \\
\hline observes the law, maintains public order - violates public order & 0.619 & 0.759 \\
\hline respects (destructs) Russian national traditions and culture & 0.991 & -0.125 \\
\hline exercises fully rights and freedoms - discriminated & 0.901 & 0.395 \\
\hline altruistic, capable of self-sacrifice - egoistic & 0.995 & -0.032 \\
\hline non-irritant - irritant, inspiring disgust & 0.991 & -0.125 \\
\hline trusty - mistrustful & 0.738 & -0.674 \\
\hline (not) evoking fear & 0.995 & 0.043 \\
\hline (not) evoking compassion & -0.865 & -0.393 \\
\hline evoking superiority - evoking humility & 0.886 & 0.463 \\
\hline associated with ethnic diversity- associated with national exceptionality & 0.959 & -0.045 \\
\hline stands together, adopts way of life, behavior and habits - stands apart, has different way of life & 0.901 & 0.395 \\
\hline evoking respect (enmity) & 0.359 & -0.928 \\
\hline (does not) represents a threat for the national security and social-economic development of Russia & 0.995 & 0.043 \\
\hline is (not) a source of interethnic conflicts and tension & 0.998 & -0.023 \\
\hline
\end{tabular}

The semantic space, built on the base of factor analysis, was described by the sense of factors and coordinates projections on the factorial axes and visualized the interrelations between objects and descriptors. As we may see on the Figure 1, the roles of 'migrant worker' and 'refugee' ( 3 and 4) were highly opposed to other roles by first factor. The points of descriptors were located in the positive range of values while near them there was only one descriptor- '(not) evoking pity and compassion'. By second factor the position of 'native citizen' (6) was described by characteristics 'close', 'subtle', 'trusty', and was opposed to other positions, among which the most distant was 'tourist' with attributes 'law-abiding', 'peaceable', 'rich', 'enjoy of rights and (Figure 1). Hence, all role positions were divided into three groups. The first group consisted of positions 1, 2 and 5 ('nearest person representative of other nationality', 'close friend' and 'tourist'), the second - 3 and 4 ('migrant worker' and 'refugee') and the third group was represented by only one position 6 - 'native citizen of Russia'. We may conclude that all positions except 'native citizen' were perceived as more or less 'alien'. However, if the first group positions were evaluated positively and even better than 'native citizen', the second group represented images the most negatively perceived.

Taking into account the similarity of factor structures, we found possible to compare semantic spaces built for different social groups (by age, sex and region) and extract two general and three unique models, describing semantic associations between role positions and constructs in the space, defined by the sense of principal factors.

The first model included data of united sample, samples for middle age and seniors, Altaisky krai and Omskaya oblast. In this model, the first factor accumulated variables, related to intellectual and cultural development, enrichment or destruction of Russian traditions and culture, threat for national security and socialeconomic development, interethnic conflicts and tension. Depending on the weight of the loadings this factor was titled 'factor of cultural development and security', 'factor of social attraction or rejection', 'factor of conflictness and peacefulness'. The second factor reflected the sense of national identification and was called 'factor of accordance to Russian mentality'. All spaces within this model possessed common features, such as: opposition of 'native citizen' and all other positions, its description as 'naïve', 'close', 'trusty'; association in one group of three positions - "nearest person of other nationality', 'representative of other ethnos, who was born and constantly lives in region' and 'tourist', perceived as law-abiding, peaceable, rich, not discriminated in rights and freedoms; evoking the sense of national exceptionality; the similar perception of 'refugee' and 'migrant worker', associated with descriptor 'evoke pity and compassion'. 


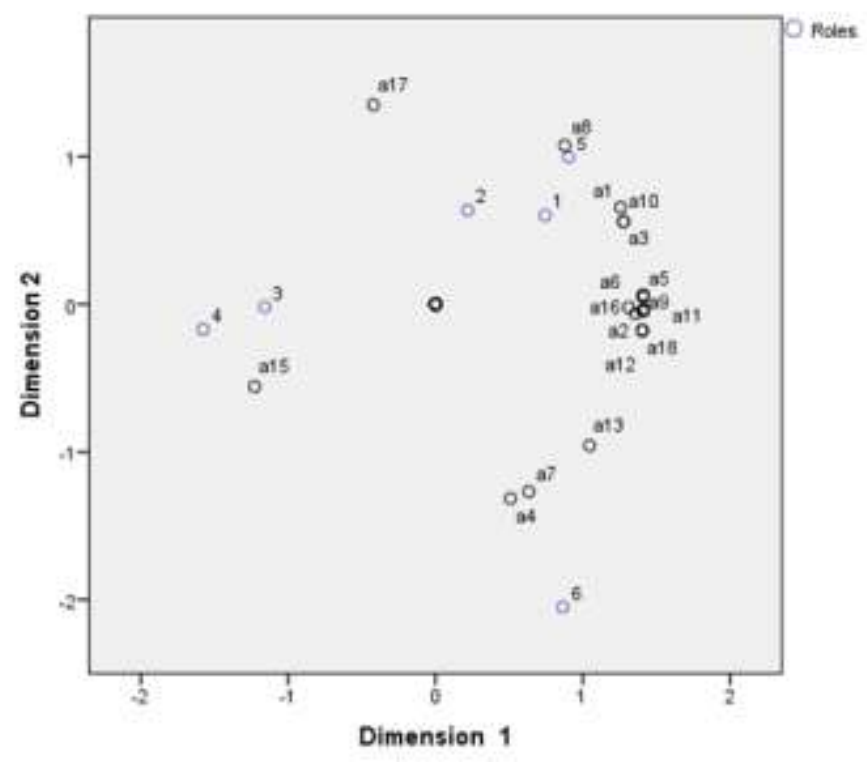

Fig. 1: Semantic space with scores for role positions and descriptors. Roles are marked as blue points: 1 - 'nearest person of other nationality', 2 - 'representative of other ethnos, who was born and constantly lives in region', 3- 'refugee', 4-

'migrant worker ', 5 - 'tourist', 6 -'native (aboriginal) citizen of Russia'. Descriptors: 1 - peaceful - aggressive; 2 - strong - weak; 3 - poor - rich; 4- subtle, enterprising - naïve, artless; 5- well-wishing - hostile; 6-intellectually and culturally developed - intellectually and culturally poor; 7- close - alien; 8- breaks the law, violates public order - observes the law, maintains public order;9- respects Russian national traditions and culture - destructs Russian national traditions and culture; 10 -discriminated - exercises fully rights and freedoms; 11- egoistic, devoted to one's own interests and advancement - altruistic, capable of self-sacrifice; 12- irritant, inspiring disgust - non-irritant; 13 - trusty - mistrustful; 14(not)evoking fear; 15- (not) evoking compassion; 16- evoking superiority (humility); 17- associated with national exceptionality - associated with national diversity; 18- stands apart, has different way of life -stands together, adopts way of life, behavior and habits; 19- inspiring respect - inspiring enmity; 20- represents a threat for national security, socialeconomic development of Russia - does not represent a threat; 21 - is (not) a source of interethnic conflicts and tension.

The second model was relevant for men and young people of less than 30 years old. In this model the first factor was identical to the first factor of the first model, while the second factor reflected the sense of 'national pride and dignity' and was described by contradictory poles - poor and evoking humility but strong and evoking the sense of national exceptionality. This factor was called as the factor of 'nationalism-cosmopolitism'. The semantic space of this type contained the opposition of the role of 'tourist', perceived as rich, law-abiding, enjoying rights and freedoms, associated with national diversity, to other positions. 'Native citizen of Russia' was close to 'nearest person of other nationality', both roles were interpreted as 'close', 'strong', but at the same time 'naïve, simple-minded'.

The third model corresponded to woman's type of perception and was characterized by holistic view of ethnic images, where all positions and the majority of descriptors were strictly tied. The roles of 'tourist' and 'nearest person of other nationality' composed the united group and were evaluated as strong, peaceable, lawabiding and evoking the feeling of national exceptionality. The roles of 'native citizen' and 'refugee' were also semantically tied, both positions evoked pity and compassion. On the other side of the space there was a group of descriptors including characteristics, such as 'hostile', 'intellectually and culturally undeveloped', 'poor' and 'subtle', which in the woman's conscience were very similar, practically synonymic but not evidently related to any ethnic image.

The fourth model uncovered the specific perception of inhabitants of the Republic of Altai. The first factor in the model was the same as in other models whereas the second factor was concentrated on social inequality and social justice. Unlike other regions, in this space the roles of 'migrant worker' and 'refugee' were distanced, the position of 'refugee' evoked pity and compassion and was perceived neutrally by descriptors of 'security' group. 'Migrant worker' was located in both zones of "social justice" and "conflict". Native citizens, nearest 
persons and regional ethnic groups formed semantically unified node - 'inoffensive" but 'discriminated'. The role of 'tourist' was perceived as the most attractive.

The fifth model was relevant for the inhabitants of the Krasnoyarsky krai. The appropriate semantic space had the combination of ideas of social and national security with national identification in the first factor on the base of the opposition 'close-alien'. The second factor was concentrated on the axes of social inequality - social justice, resulting from the characteristics of national character. The positions of 'nearest person of other nationality', 'representative of other ethnos, who was born and constantly lives in region' and 'tourist' were located very close to each other and perceived as 'rich', 'strong', 'not discriminated', 'evoking the feeling of national diversity', 'inoffensive', but 'alien'. The positions of 'native citizen' and 'refugee' were also semantically approximate, described by characteristics 'naïve, simple-minded', 'evoking pity and compassion', 'discriminated against', 'poor' and 'weak'. In the light of sense of factors, these images were perceived as 'peaceable' but 'alien'. The role of 'migrant worker' was isolated in the zone of negative values by the first factor and low positive values by the second factor that might be interpreted as 'offensive' and 'alien' but not related to poverty and discrimination.

\section{Conclusion}

Mental representations and perception of people from other nationalities are construed on the base of personal experience of interaction with representatives of different nationalities and stereotypes, both positive and negative, translated by mass-media, mass culture and political elites. The contents of theses stereotypes are mostly related to evaluation of potential risk and threat for national security, interethnic conflicts and tension, social inequality, cultural and intellectual development. The influence of stereotypes is flattened in family and friendly relations and intensified in conditions of assessment of unknown people especially with low or illegal social status. The self-perception of inhabitants of Russia is contradictory and inconsistent. On one hand, native residents of Russia retain paternalistic, inherited from soviet period vision of international relations based on representations about their national uniqueness and superiority. On the other hand, they demonstrate a low selfesteem which is usually caused by the low standard of their living, civil rights violations, differences of educational achievements, inadequate housing and social exclusion. Despite general semantic perception mechanisms, regional mentalities are significantly differentiated that is reflected in social images and stereotypes of their residents.

\section{Acknowledgement}

This work was supported by the Ministry of Education and Science of the Russian Federation, the State Order for the scientific research "Civic and ethic identities in the system of maintenance of social security among population in border territories of Russia" [№28.1475.2014K].

\section{References}

[1] A. Paivio, "Dual coding theory: Retrospect and current status", Canadian Journal of Psychology/Revue canadienne de psychologie, vol. 45, pp.255-287, 1991.

[2] S.M. Kosslyn, "Mental imagery", in Visual cognition and action, D. N. Osherson, S. M. Kosslyn, and J. M. Hollerbach (Eds), Cambridge, MA, 1990, pp. 74-97.

[3] A.N. Leontviev, Activity. Conscience. Personality, Moscow, Russia: Smisl, Academia, 2005.

[4] E. Artemieva, Basis of subjective semantics, Moscow, Russia: Nauka, 1999.

[5] B. Anderson, Imagined communities: reflections on the origin and spread of nationalism, London: Verso, 2016.

[6] H. Arendt, The Promise of Politics, New York: Schocken Books, 2007.

[7] J. Baudrillard, The vital illusion. New York: Columbia University Press, 2000. https://doi.org/10.7312/baud12100

[8] Z. Baumann, Thinking Sociologically. An introduction for Everyone, Cambridge, 1990.

[9] U. Beck, The Reinvention of Politics. Rethinking Modernity in the Global Social Order, Cambridge, 1996.

[10] P. Bourdieu, "Structures, habitus, practices", in P. Bourdieu. The logic of practice, Stanford, 1990, pp. 52-79. 
[11] S. Moscovici, Social representations: Essays in social psychology, NYU Press, 2001.

[12] P. Sorokin, Man, civilization, society, Moscow: Politizdat, 1992.

[13] M. Halbwaks, Social classes and morphology, Saint-Petersburg: Aleteya, 2000.

[14] F. Fransella, R. Bell, D.A, Bannister, A manual for repertory grid technique, 2nd ed., Chichester: Wiley, 2004.

[15] V.F. Petrenko, Foundations of psychosemantics, 2nd ed., Saint-Petersburg: Aleteya, 2005. 